\title{
CONCEPTS
}

\section{Palliative Care's Role in Austere Medicine}

\author{
Justin D. Woods, $\mathrm{MD}^{1}$; Betsy N. Woods, $\mathrm{MSN}^{2}$ \\ ${ }^{1}$ Tulane University School of Medicine, New Orleans, Louisiana; ${ }^{2}$ School of Nursing, Samuel Merritt University, San Mateo, California
}

\begin{abstract}
The integration of palliative care across multiple domains has increased in recent years, particularly in austere medical settings such as humanitarian crises and low- and middle-income countries. Providing relief from suffering through a multifaceted approach for patients in austere environments is both an ethical imperative and perfectly suited to palliative care's ethos. Practical resources have been developed that can guide many levels of medical practitioners in the administration of palliative care techniques in these settings. Further education and advocacy continue to be needed both for the promotion of primary palliative care and for access to certain classes of medications by which to deliver this care.
\end{abstract}

Keywords: symptom management, primary palliative care, wilderness medicine

\section{Introduction}

The rapid growth of the global population has seen a concurrent increase in the number of people living, working, traveling, and recreating in areas that are considered austere, or resource limited, environments, requiring the medical community to adapt and grow with the challenge of caring for patients in these settings. Palliative care is an integral aspect of quality medical care that has been expanding into austere medical settings over the past decade. The information presented in this article will clarify what palliative care is and how its inclusion in care delivery in austere settings such as the wilderness, humanitarian crises, and low- and middleincome countries (LMICs) is beneficial for both patients and providers.

\section{Background}

Palliative care is a practice approach that improves the quality of life for patients with both acute and chronic life-threatening or life-limiting conditions by preventing and relieving suffering, whether it be physical,

Corresponding Author: Justin D. Woods, MD, Tulane University School of Medicine, 6823 St. Charles Avenue, New Orleans, LA 70118; e-mail: jwoods8@tulane.edu.

Submitted for publication July 2021.

Accepted for publication December 2021. psychosocial, or spiritual. $^{1,2}$ Key elements of palliative care include relief from pain and other distressing symptoms, holistic care, and an approach that affirms life yet does not fear death. Palliative care can be implemented in conjunction with therapies intended to prolong life and can therefore be offered at any point along the continuum of care. ${ }^{3}$

Palliative medicine has experienced significant growth in the past few decades, expanding from its roots in the hospice movement to a designation as a separate medical subspecialty with growing global recognition as international organizations acknowledge palliative care as an essential component of healthcare. ${ }^{3}$ As the field of palliative medicine grows, its role and integration into various settings, such as patients' homes, outpatient clinics, emergency departments, and telemedicine, have been explored. Recently, the role and benefits of palliative care in austere medicine, defined as the practice of medicine in resource-limited environments, ${ }^{4}$ has been increasingly discussed, particularly in the context of humanitarian crises and LMICs. Although some palliative care techniques, such as pain control, are not unique and are used by various levels of practitioners in wilderness environments, palliative care as a specialty has yet to be discussed in expeditionary or search and rescue contexts. However, these wilderness settings are another austere environment in which certain aspects of palliative care, such as a holistic approach and thorough management of pain and other distressing symptoms, can benefit patients. 


\section{Benefits of Integrating Palliative Care in Austere Medical Settings}

Because palliative care can be provided with a modest amount of medications and equipment, most of which are inexpensive and globally accessible, ${ }^{1}$ it is feasible in resource-limited settings and offers benefits to both patients and providers.

\section{WILDERNESS SETTINGS}

Wilderness medicine is characterized by the provision of care in remote settings with limited resources, the need for improvisation, reliance on clinical examination and judgment, and delayed evacuation to definitive care., By definition, wilderness medicine can occur in many contexts, but for the purposes of this paper, references to wilderness medicine and wilderness environments will be referring to medical care in settings such as search and rescue operations and expeditions. In these situations, taking a palliative care approach of focusing on thoroughly managing symptoms such as pain and anxiety can be beneficial to patients. This is especially important during technical extrications and prolonged evacuations to definitive care. Negative effects of undertreated pain include a significant stress response, increased sensitivity to pain the longer the pain remains uncontrolled, and an increased risk of developing posttraumatic stress disorder. ${ }^{7}$ Negative effects of undertreated anxiety may also include hyperalgesia, in addition to the development of other distressing symptoms such as palpitations, nausea and vomiting, and shortness of breath. ${ }^{7-9}$

Medical providers in wilderness settings can use the Wilderness Medical Society guidelines for analgesic care in remote environments to effectively manage pain. ${ }^{7}$ This stepwise approach encourages all providers to offer at least some form of pain management, starting with the safest and most accessible interventions before escalating care. ${ }^{10}$ This involves using nonpharmacological interventions, such as comforting techniques and PRICE therapy (protection from further injury, rest, ice, compression, elevation) when appropriate before advancing to nonopioid medications, followed by opioid administration by providers with appropriate licensing. Implementing PRICE therapy in austere settings can be accomplished through improvisation. Splints can be created with items such as trekking poles to protect areas from further injury, and snow, ice, or cold water can be used to cool an injured extremity to relieve pain and reduce swelling. Compression can be attained using a compression bandage, if available, or an article of stretchy clothing wrapped around the extremity and tied securely, checking for continued perfusion beyond the wrap. For managing anxiety, nonpharmacological interventions, encompassed in the principles of psychological first aid, should be the mainstay of treatment. These include providing a safe physical space, offering reassurance and support, listening to the patient, reviewing the plan of care, and using relaxation techniques such as distraction and meditation. ${ }^{7,8}$

\section{HUMANITARIAN CRISES}

Palliative care has an important role in humanitarian crises. This has been acknowledged in the Sphere Handbook-one of the most widely used publications on principles and standards for humanitarian response-where palliative care is listed as an essential element of healthcare, and by the World Health Organization (WHO), which states that humanitarian responses that do not include palliative care are incomplete and unethical. ${ }^{1,11}$ There are multiple humanitarian scenarios in which palliative care should be considered: in mass casualty events where resource limitations affect care delivery; in protracted crises where care for life-limiting conditions has been interrupted; and in outbreaks of disease where mortality rates are high and therapeutic interventions are limited. ${ }^{12}$ In each of these scenarios, palliative care can be provided using the palliative care package from the Lancet commission on global access to palliative care and pain relief or the WHO essential package of palliative care medications and equipment (Table 1). These packages are simple enough to be used by physicians and nurses with basic symptom management training.

\section{Mass Casualty Events}

In mass casualty events, healthcare providers frequently care for patients who are actively dying or whose poor chance of survival has precluded them from receiving limited life-sustaining resources. In these cases, implementing palliative care measures to ensure comfort and dignity during death fulfills the ethical imperative to aid these highly vulnerable patients.

Research investigating what patients and families consider to be a "good death" has shown that the key elements are 1) clear communication from healthcare providers, 2) adequate symptom management, 3) time with loved ones, and 4) preparation for death. ${ }^{8}$ Although achieving these elements may be difficult in a humanitarian crisis, steps can be taken to further these aims. When possible, healthcare providers should promptly and clearly communicate prognosis to patients and families, with identification of a lead decision maker in situations where there are multiple 
Table 1. Essential package of palliative care for humanitarian emergencies and crises

\begin{tabular}{|c|c|c|c|c|}
\hline \multirow[t]{2}{*}{ Interventions } & \multicolumn{4}{|c|}{ Inputs } \\
\hline & Social supports & Medicines $^{a}$ & Equipment & Human resources ${ }^{b}$ \\
\hline $\begin{array}{l}\text { Prevention and relief of pain or other physical } \\
\text { suffering, }{ }^{c} \text { acute or chronic, related to } \\
\text { humanitarian emergencies or crises }\end{array}$ & & $\begin{array}{l}\text { Amitriptyline, oral } \\
\text { Bisacodyl (senna), oral } \\
\text { Dexamethasone, oral and injectable } \\
\text { Diazepam, oral and injectable } \\
\text { Diphenhydramine (chlorpheniramine, cyclizine, or } \\
\quad \text { dimenhydrinate), oral and injectable } \\
\text { Fluconazole, oral } \\
\text { Fluoxetine, oral } \\
\text { Furosemide, oral and injectable } \\
\text { Haloperidol, oral and injectable } \\
\text { Hyoscine butylbromide, oral and injectable } \\
\text { Ibuprofen (naproxen, diclofenac, or meloxicam), oral } \\
\text { Lactulose (sorbitol or polyethylene glycol), oral } \\
\text { Loperamide, oral } \\
\text { Metaclopramide, oral and injectable } \\
\text { Metronidazole, oral, to be crushed for topical use } \\
\text { Morphine, oral immediate release and injectable } \\
\text { Naloxone, injectable } \\
\text { Omeprazole, oral } \\
\text { Ondansetron, oral and injectable }{ }^{d} \\
\text { Oxygen } \\
\text { Paracetamol, oral } \\
\text { Petroleum jelly }\end{array}$ & $\begin{array}{l}\text { Pressure-reducing mattresses } \\
\text { Nasogastric drainage and feeding tubes } \\
\text { Urinary catheters } \\
\text { Opioid lock boxes } \\
\text { Flashlights with rechargeable batteries (if no } \\
\quad \text { access to electricity) } \\
\text { Adult diapers or cotton and plastic }\end{array}$ & $\begin{array}{l}\text { Doctors (with basic palliative care } \\
\text { training) } \\
\text { Nurses (with basic palliative care } \\
\text { training) } \\
\text { Community health workers (if } \\
\text { available) }\end{array}$ \\
\hline $\begin{array}{l}\text { Prevention and relief of psychological suffering, }{ }^{e} \\
\text { acute or chronic, related to humanitarian } \\
\text { emergencies or crises }\end{array}$ & & $\begin{array}{l}\text { Amitriptyline, oral } \\
\text { Dexamethasone, oral and injectable } \\
\text { Diazepam, oral and injectable } \\
\text { Diphenhydramine (chlorpheniramine, cyclizine or } \\
\quad \text { dimenhydrinate), oral and injectable } \\
\text { Fluoxetine, oral } \\
\text { Haloperidol, oral and injectable } \\
\text { Lactulose (sorbitol or polyethylene glycol), oral }\end{array}$ & Adult diapers or cotton and plastic & $\begin{array}{l}\text { Doctors (with basic palliative care } \\
\text { training) } \\
\text { Nurses (with basic palliative care } \\
\text { training) } \\
\text { Social workers or psychologists } \\
\text { Community health workers (if } \\
\quad \text { available) }\end{array}$ \\
\hline $\begin{array}{l}\text { Prevention and relief of social suffering, acute } \\
\text { or chronic, related to humanitarian } \\
\text { emergencies or crises }\end{array}$ & $\begin{array}{l}\text { Income and } \\
\text { in-kind support }\end{array}$ & & & $\begin{array}{l}\text { Social workers } \\
\text { Community health workers (if } \\
\text { available) }\end{array}$ \\
\hline $\begin{array}{l}\text { Prevention and relief of spiritual suffering } \\
\text { related to humanitarian emergencies or crises }\end{array}$ & & & & Local spiritual counselors \\
\hline
\end{tabular}

${ }^{a}$ Based on WHO Model List of Essential Medicines 2015. Acceptable alternative medicines are in parentheses.

${ }^{b}$ Doctors may be local or foreign and may be surgeons, anesthesiologists, intensivists, infectious disease specialists, pediatricians, general practitioners, palliative care specialists, or others. Nurses may include nurse-anesthetists.

${ }^{c}$ Other physical suffering includes breathlessness, weakness, nausea, vomiting, diarrhea, constipation, pruritus, bleeding, wounds, and fever.

${ }^{d}$ Only at hospitals that provide cancer chemotherapy or radiotherapy.

${ }^{e}$ Psychological suffering includes anxiety, depressed mood, confusion or delirium, dementia, and complicated grief.

${ }^{f}$ Only for patients living in extreme poverty and for 1 caregiver per patient. Includes cash transfers to cover housing, children's school tuition, transportation to healthcare facilities or funeral costs; food packages; and other in-kind support (blankets, sleeping mats, shoes, soap, toothbrushes, toothpaste).

Reprinted with permission. 
caregivers. ${ }^{8,13}$ Adequate management of common endof-life symptoms such as pain, dyspnea, and agitation is crucial and can be achieved with opioids such as morphine, benzodiazepines such as lorazepam, and haloperidol. ${ }^{8}$ Because symptom control is possible in almost any setting by using various routes for medication administration such as rectal, sublingual, and subcutaneous, dying patients can be cared for outside of the hospital; when paired with having nonmedical personnel stay with patients and their families, this can help offload medical staff and divert dying patients from overburdened hospitals. ${ }^{8,13}$

Although spending time with loved ones and preparing for death can be especially challenging in disaster contexts when the environment is chaotic and patients may die rapidly, efforts should be made to locate family members and help patients and families prepare for death with interventions such as culturally appropriate spiritual care and memory making, particularly if the patient is a child. ${ }^{8}$

Although palliative care may be of highest priority for patients triaged as imminently dying, patients triaged to immediate life-saving interventions also frequently need symptom management and psychosocial support, as do patients lingering with nonsurvivable injuries and complications. Palliative care is particularly valuable when surgical and life-sustaining resources are inadequate, as is often seen in sudden-onset disasters. ${ }^{1}$ Preparing disaster response teams with the adequate training and supplies to relieve suffering and to recognize and treat end-of-life symptoms is a necessary step toward a comprehensive disaster response plan.

\section{Protracted Crises}

In protracted crises, healthcare workers have traditionally focused on treating patients with acute and curable conditions owing to limited resources, whereas the needs of those with life-limiting chronic and incurable conditions are largely, or even completely, unmet. ${ }^{14,15}$ Many of those unmet needs could be addressed by palliative care. An illustration of this is seen in the Rohingya refugee crisis in Bangladesh, where many refugees have been found to have substantial neglected suffering, such as pain and caregiver strain, that could be mitigated by palliative care services provided by community health workers with palliative care training. ${ }^{14,16}$ These services could include routine pain assessments; treatment of severe pain with locally manufactured oral morphine; access to essential medical supplies such as catheters and pressure-reducing mattresses, which are also manufactured locally; and caregiver training and psychosocial support. $^{14}$

\section{Disease Outbreaks}

Palliative care can benefit patients during outbreaks of disease, where the management of distressing symptoms is at times neglected in the haste to save lives, although palliative care has more to offer beyond just the relief of suffering. This is seen with intensive control of symptoms such as diarrhea and vomiting, which not only reduces suffering but may also improve survival rates and provide better infection control. ${ }^{1}$ Furthermore, in situations where therapeutic interventions are limited and curative treatments may not exist, palliative care may be the only acceptable option. ${ }^{17}$ This was seen during the Ebola epidemic, where palliative care was frequently the only form of care available to patients. ${ }^{18}$ Treatment of psychosocial suffering, which can be caused by both illness and the response to it, is another domain of palliative care that can be applied during outbreaks of disease. Fear, anxiety, depression, loss of self-esteem, a sense of powerlessness, and feelings of dehumanization may be experienced by patients in relation to isolation, the threat of a potentially fatal illness, and stigmatization during epidemics. ${ }^{1,13}$ Psychosocial support can be given to patients by training healthcare providers and volunteers in psychological first aid, providing regular information to patients about their condition, organizing isolation wards so that patients can communicate with family at a distance or via technology, recruiting local mental health providers to offer culturally appropriate care, and ensuring access to antidepressants and benzodiazepines as appropriate. Forming partnerships with local religious leaders with infection control training who can visit patients on request and conducting education in the community about the disease to reduce fear and stigma are also helpful. ${ }^{1}$ Lastly, pandemics can produce ethically challenging situations regarding the allocation of scarce resources, and providers trained in palliative care are well prepared to discuss preferences and advance care plans with patients and their caregivers, which can reduce resource strain. ${ }^{13}$

\section{LOW- AND MIDDLE-INCOME COUNTRIES}

One of the broadest austere settings where palliative care can benefit patients is LMICs, where medical care frequently occurs in resource-constrained environments with significant unrelieved suffering. More than $80 \%$ of the 25.5 million patients who died with serious-health related suffering in 2015 were in LMICs with limited to nonexistent access to palliative care and pain relief. ${ }^{2}$ As such, improving access to palliative care in these countries can reduce significant end-of-life suffering. By providing pain and symptom management, palliative care 
can also help patients suffering from preventable, infectious, and poverty-associated conditions related to health systems that fail to provide access to preventative services and life-saving treatments and interventions. ${ }^{2} \mathrm{~A}$ prime example of this is the use of palliative care for cancer patients in LMICs, where late detection is common and there is insufficient access to specialists and treatments. ${ }^{19,20}$

Another unique role of palliative care in LMICs is as a poverty-reduction strategy, as the cost of care for incurable diseases often results in entire communities struggling to absorb medical expenses. Homes, livestock, and other assets are often sold to pay for medical care, which can quickly cause a family to slip into poverty or destitution. Added to this are indirect costs such as missed wages from family members caring for the patient and lost opportunities for children who are pulled out of school because the family can no longer afford the fees owing to medical expenses. These can all contribute to financial losses that are passed to future generations. ${ }^{21}$ An extended cost-effectiveness analysis of the Lancet commission's palliative care package found that universal implementation of the package can reduce the risk of catastrophic medical expenses, which is one of the major causes of impoverishment in LMICs. The Lancet commission's palliative care package costs between $\$ 2$ and \$16 US per capita per year and is one of the least expensive components of the essential universal health coverage package. ${ }^{2}$ As such, palliative care can help to reduce the financial burden and progression into poverty caused by incurable diseases by offering patients and families a more cost effective alternative than continuing to look for a cure that is not available. ${ }^{21,22}$ Palliative care in the community may also offer cost savings in LMICs by reducing end-of-life hospital admissions. ${ }^{2}$

\section{BENEFIT TO PROVIDERS}

It is important to note that the provision of palliative care can be beneficial not just for patients, but for healthcare providers as well. In interviews conducted with healthcare providers who had responded to natural disasters, the inability to alleviate patient suffering was believed to exacerbate the trauma of the event. ${ }^{23}$ Similarly, interviews with healthcare providers who had cared for Ebola patients revealed that providers continued to be deeply disturbed by their experiences of witnessing patients suffering immensely without relief. Therefore, a strong palliative care response in any situation likely to have significant suffering may help healthcare providers mitigate their own moral distress and vicarious trauma by empowering them to provide effective symptom management. ${ }^{24}$

\section{Barriers to Implementation}

There are barriers to providing palliative care in austere settings, and although some have been addressed, others continue to be a challenge. In wilderness settings, barriers are generally related to pain management and include lack of medications, challenges related to carrying and administering opioid analgesics, insufficient pharmacologic knowledge, concerns about addiction or adverse side effects from medications, and the potential of masking clinical deterioration with the administration of certain medications. ${ }^{10,15}$ In LMICs, limited access to opioid medications is one of the most significant barriers; although nonopioid medications are an integral aspect of symptom management, opioid medications are often required to provide quality palliative care. Currently, $83 \%$ of countries have limited to no access to opioids, with LMICs accounting for just $10 \%$ of global opioid use. $^{3}$ Other barriers to palliative care in LMICs include lack of policies that support the provision of palliative care, little to no knowledge of palliative care among healthcare professionals, and cultural differences in the approach to serious illness or death that affect the delivery and acceptance of palliative care. ${ }^{3}$ Providing palliative care in humanitarian emergencies may include the same challenge of access to opioids depending on location, in addition to the difficulty of triaging patients to determine who should receive curative-focused care versus a comfort-focused approach. A lack of palliativespecific training is a barrier to the implementation of palliative care in all austere settings.

Although the barriers to integrating palliative care into austere medicine may seem daunting, strategies exist to minimize or eliminate these barriers. First, efforts are being undertaken on a global scale to develop policies that support the provision of palliative care via laws that acknowledge palliative care as part of the healthcare system, clinical guidelines for the delivery of palliative care, and national strategies for palliative care implementation. Second, the palliative care community and related human rights organizations have been advocating for an appropriate balance between the prevention of illicit use of controlled substances and the human right to access medications for pain relief-in particular, opioids for palliative care in LMICs. ${ }^{2,3}$ Improving the availability of licit opioids for palliative care can benefit patients in all of the previously discussed austere environments. For humanitarian relief efforts, responders can refer to the WHO model guidelines for transporting controlled medications across international borders for emergency medical care. Cultural barriers can be addressed through selfreflection on personal cultural values, an attitude of 
humility and respect, and consulting and collaborating with local healthcare providers to deliver culturally sensitive palliative care. ${ }^{25}$ One of the greatest ways to improve access to palliative care in any austere environment is to provide education on primary palliative care (PPC). This is defined as palliative care provided by primary healthcare workers in settings prior to specialized palliative care access. ${ }^{26}$ Efforts are being undertaken globally to provide this education through international partnerships and even remote telehealth education. By furthering PPC education for wilderness first responders, humanitarian aid workers, and medical providers in LMICs, the likelihood increases that there will be a knowledgeable individual nearby when needed.

\section{Available Resources}

Organizations and healthcare providers across multiple specialties have developed some excellent resources that are useful for both PPC education and anyone interested in learning more about the integration and implementation of palliative care in austere medicine. For palliation in wilderness environments, the Wilderness Medical Society practice guidelines for acute pain management in remote settings provides guidance on ideal medication selection for wilderness use, along with a stepwise pain management pyramid for providing analgesic care for the typical backcountry patient. For palliative care in humanitarian emergencies and LMICs, the WHO guide to palliative care in humanitarian emergencies and the report by the Lancet commission on global access to palliative care and pain relief are replete with useful information. Both include an essential palliative care package of medications, equipment, and human resources developed specifically for use in LMICs, along with practical considerations for implementation. The WHO guide also contains a sample palliative care curriculum for training humanitarian responders, which can help to further PPC education. For more in-depth guidance, A Field Manual for Palliative Care in Humanitarian Crises is a tremendous resource focused on providing instruction to those not specifically trained in palliative care. A network of global partners working to further palliative care in humanitarian aid settings through research, advocacy, and education has also been developed by the Palliative Care in Humanitarian Aid Situations and Emergencies organization. All of these resources and more, such as virtual webinars, are available to help further PPC education and, where needed, address cross-cultural understanding of factors that affect the delivery of palliative care.

\section{Conclusions}

It is important to note that the need to integrate palliative care in austere medical settings in no way replaces the importance of providing mortality-reducing care when available. Instead, both types of care should be delivered conjointly whenever possible. This can be achieved by taking steps to educate all medical practitioners in PPC techniques. Gaining this knowledge base should result in both increased quality of care in austere settings and achievement of the ethical imperative to reduce suffering in all care settings. This transformation will take the concerted global effort of individuals and organizations to advocate for PPC education and the resources necessary for its implementation.

Author Contributions: Drafting of the manuscript (JDW, BNW); critical revision of the manuscript (JDW, BNW); approval of final manuscript (JDW, BNW).

Financial/Material Support: None.

Disclosures: None.

\section{References}

1. World Health Organization. Integrating palliative care and symptom relief into the response to humanitarian emergencies and crises: a WHO guide. Available at: https://apps.who.int/iris/bitstream/ handle/10665/274565/9789241514460-eng.pdf?ua=1. Accessed May 11, 2021.

2. Knaul FM, Farmer PE, Krakauer EL, De Lima L, Bhadelia A, Kwete XJ, et al. Alleviating the access abyss in palliative care and pain relief - an imperative of universal health coverage: the Lancet Commission report. Lancet. 2018;391(10128):1391-454.

3. Connor SR, ed. Global Atlas of Palliative Care. 2nd ed. London: Worldwide Palliative Care Alliance, 2020. Available at: http://www. thewhpca.org/resources/global-atlas-on-end-of-life-care. Accessed October 5, 2021.

4. Auerbach PS, ed. Wilderness Medicine. 7th ed. Philadelphia, PA: Elsevier; 2017.

5. Sward DG, Bennett BL. Wilderness medicine. World J Emerg Med. 2014;5(1):5-15.

6. Backer HD. What is wilderness medicine? Wilderness Environ Med. 1995;6(1):3-10.

7. Russell KW, Scaife CL, Weber DC, Windsor JS, Wheeler AR, Smith W, et al. Wilderness Medical Society practice guidelines for the treatment of acute pain in remote environments: 2014 update. Wilderness Environ Med. 2014;25(4 Suppl):S96-104.

8. Waldman E, Glass M. A Field Manual for Palliative Care in Humanitarian Crises. Oxford University Press, 2020.

9. Thibodeau MA, Welch PG, Katz J, Asmundson GJG. Pain-related anxiety influences pain perception differently in men and women: a quantitative sensory test across thermal pain modalities. Pain. 2013;154(3):419-26.

10. Surrett G, Franklin J, Wedmore I. Pain control in austere settings. Curr Sports Med Rep. 2015;14(2):117-22.

11. Sphere Association. The Sphere Handbook: Humanitarian Charter and Minimum Standards in Humanitarian Response. 4th ed. Rugby, Warwickshire: Practical Action Publishing, 2018. 
12. Powell RA, Schwartz L, Nouvet E, Sutton B, Petrova M, Marston J, et al. Palliative care in humanitarian crises: always something to offer. Lancet. 2017;389(10078):1498-9.

13. Etkind SN, Bone AE, Lovell N, Cripps RL, Harding R, Higginson IJ. The role and response of palliative care and hospice services in epidemics and pandemics: a rapid review to inform practice during the COVID-19 pandemic. J Pain Symptom Manage. 2020;60(1):e31-40.

14. Doherty M, Khan F. Neglected suffering: the unmet need for palliative care in Cox's Bazar. Available at: https://reliefweb.int/sites/ reliefweb.int/files/resources/Neglected\%20Suffering.pdf. Accessed May 6, 2021.

15. Schneider M, Pautex S, Chappuis F. What do humanitarian emergency organizations do about palliative care? A systematic review. Med Confl Surviv. 2017;33(4):263-72.

16. Doherty M, Power L, Petrova M, Gunn S, Powell R, Coghlan R, et al. Illness-related suffering and need for palliative care in Rohingya refugees and caregivers in Bangladesh: a cross-sectional study. PLoS Med. 2020;17(3):e1003011.

17. Rosoff P. Caring for the suffering: meeting the Ebola crisis responsibly. Am J Bioeth. 2015;15(4):26-32.

18. Smith J, Aloudat T. Palliative care in humanitarian medicine. Palliat Med. 2017;31(2):99-101.

19. Hannon B, Zimmermann C, Knaul FM, Powell RA, MwangiPowell FN, Rodin G. Provision of palliative care in low- and middle-income countries: overcoming obstacles for effective treatment delivery. J Clin Oncol. 2016;34(1):62-8.
20. Price AJ, Ndom P, Atenguena E, Nouemssi JPM, Ryder RW Cancer care challenges in developing countries. Cancer. 2012;118(14):3627-35.

21. Anderson RE, Grant L. What is the value of palliative care provision in low-resource settings? BMJ Glob Health. 2017;2(1): $\mathrm{e} 000139$.

22. Reid EA, Kovalerchik O, Jubanyik K, Brown S, Hersey D, Grant L. Is palliative care cost-effective in low-income and middle-income countries? A mixed-methods systematic review. BMJ Support Palliat Care. 2019;9(2):120-9.

23. Amir T, Yantzi R, de Laat S, Bernard C, Elit L, Schuster-Wallace C, et al. Dying alone is hard anywhere in the world: palliative care in natural disaster response. Available at: https://www.elrha.org/ wp-content/uploads/2020/06/Natural_Disaster_CR_4June_2020_ FINAL_compressed-min.pdf. Accessed June 28, 2021.

24. Nouvet E, Bezanson K, Hunt M, Kouyaté S, Schwartz L, Binta Diallo F, et al. Dying in honour: experiences of end-of-life palliative care during the 2013-2016 Ebola outbreak in Guinea. Int J Humanitarian Action. 2021;6(1):10.

25. Hunt M, Nouvet E, Chénier A, Krishnaraj G, Bernard C, Bezanson K, et al. Addressing obstacles to the inclusion of palliative care in humanitarian health projects: a qualitative study of humanitarian health professionals' and policy makers' perceptions. Confl Health. 2020;14:70.

26. Munday D, Boyd K, Jeba J, Kimani K, Moine S, Grant L, et al. Defining primary palliative care for universal health coverage. Lancet. 2019;304(10199):621-2. 